\title{
Cervical screening among migrant women: a qualitative study of Polish, Slovak and Romanian women in London, UK
}

\author{
Marta Jackowska, ${ }^{1}$ Christian von Wagner, ${ }^{2}$ Jane Wardle, ${ }^{3}$ Dorota Juszczyk, ${ }^{4}$ \\ Aleksandra Luszczynska, ${ }^{5}$ Jo Waller ${ }^{6}$
}

\begin{abstract}
'PhD Student, Psychobiology Group, Department of

Epidemiology and Public Health, University College London,

London, UK

${ }^{2}$ Senior Research Associate, Cancer Research UK Health Behaviour Research Centre, Department of Epidemiology and Public Health, University College London, London, UK

${ }^{3}$ Director, Cancer Research UK Health Behaviour Research Centre, Department of Epidemiology and Public Health, University College London, London, UK

${ }^{4}$ Research Assistant, Cancer Research UK Health Behaviour Research Centre, Department of Epidemiology and Public Health, University College London, London, UK

${ }^{5}$ Associate Research Professor, Trauma, Health \& Hazards Center, University of Colorado, Colorado Springs, CO, USA and Warsaw School of Sciences and Humanities, Warsaw, Poland ${ }^{6}$ Senior Research Associate, Cancer Research UK Health Behaviour Research Centre, Department of Epidemiology and Public Health, University College London, London, UK
\end{abstract}

\section{Correspondence to}

Dr Jo Waller, Cancer Research UK Health Behaviour Research Centre, Department of Epidemiology and Public Health, University College London, 1-19 Torrington Place, London WC1E 6BT, UK; j.waller@ucl.ac.uk

Received 12 May 2011 Accepted 16 November 2011

Published Online First 4 January 2012

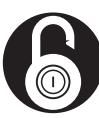

\section{OPEN ACCESS}

\section{Abstract}

Objective To explore awareness of and participation in cervical screening services in women from Poland, Slovakia and Romania living in London, UK.

Methods Three qualitative studies were carried out in London in 2008-2009: an interview study of professionals working with Central and Eastern European migrants $(n=11)$; a focus group study including three Polish, one Slovak and one Romanian focus group; and an interview study of Polish ( $n=11)$,

Slovak ( $n=7)$ and Romanian ( $n=2)$ women.

Results Awareness of the cervical screening programme was good, but understanding of the purpose of screening was sometimes limited. Some women were fully engaged with the UK screening programme; others used screening both in the UK and their countries of origin; and a third group only had screening in their home countries. Women welcomed the fact that screening is free and that reminders are sent, but some were concerned about the screening interval and the age of the first invitation. Conclusions Migrant women from Poland, Slovakia and Romania living in London vary in their level of participation in the National Health Service Cervical Screening Programme. More needs to be done to address concerns regarding screening services, and to ensure that language is not a barrier to participation.

\section{Introduction}

The rise in migration to the UK from European Union (EU) accession countries has presented challenges to the National Health Service (NHS). EU migrants intending to remain in the UK for 6 months or more are entitled to register with a general practitioner (GP), however they may not be using the NHS appropriately. ${ }^{1-3}$ Although many Central and Eastern European (CEE) migrants arriving since 2004 have

\section{Key message points}

- Central and Eastern European migrant women living in London seem to be aware of the cervical screening programme in the UK but their understanding of the test purpose varies.

- Three patterns of screening participation emerged: (1) having tests only in the UK, (2) having tests in the UK and in the country of origin and (3) having tests only in the country of origin.

- Lack of trust in the health care system, communication and language barriers were the main obstacles to participation in cervical screening.

returned home, at the end of 2008, some 665000 A8 [NB. The Czech Republic, Estonia, Hungary, Latvia, Lithuania, Poland, Slovakia and Slovenia joined the EU in 2004.] and A2 [NB. Romania and Bulgaria joined the EU in 2007.] nationals were still living in the $\mathrm{UK},{ }^{4}$ and figures from the Annual Population Survey suggest that just over $50 \%$ of $\mathrm{A} 8$ residents in the UK in 2008-2009 were women. ${ }^{5}$ Because migrant workers tend to be young adults, they have relatively few health care needs and use the NHS sporadically. ${ }^{6}$ However, this group of migrants, and in particular the Poles, may have unmet health care needs, being over-represented in manual occupations and disproportionately likely to present at emergency departments with problems more suitable to primary care. ${ }^{7}$ This is important as it could reduce their engagement with preventive health services, including the cervical screening programme.

In recent years, coverage of the NHS Cervical Screening Programme (NHSCSP) in England has been falling slightly $(78.6 \%$ in 2011 compared with $81.6 \%$ in 2002). ${ }^{8}$ Barriers to cervical screening include demographic, socioeconomic, psychological and cultural factors. ${ }^{9-18}$ Inaccuracies of 
patients' addresses and of medical records ${ }^{19-21}$ as well as inconvenient appointment times ${ }^{21-23}$ could also reduce participation.

Previous experience of screening in migrant women's home countries could influence their screening participation in the UK as well. Cervical screening programmes in many CEE countries have tended to be inadequate and poorly organised, ${ }^{24}$ which likely underlies their higher incidence and mortality from cervical cancer. ${ }^{25-29}$ Poland, Romania and Slovakia (the countries we focus on in this study) offer populationbased screening programmes, which have been initiated relatively recently (Romania: 2002; Poland: 2007, Slovak Republic: 2008). ${ }^{30}$ Poland and Slovakia have national programmes, whereas in Romania the coverage is regional. ${ }^{30}$ The participation rates are either not available or remain unclear. For example, in Poland only $28 \%$ of women participated in population-based screening, but it is estimated that a similar percentage of women attend opportunistic screening in private clinics, outside of the population-based programme. ${ }^{31}$ In addition, target age groups and screening intervals vary across the three countries. For example, the recommended screening interval is 5 years in Romania, 3 years in Slovakia and 1-3 years (depending on the woman's age) in Poland. ${ }^{3031}$ There are major challenges for screening in these countries, for instance shortcomings in providing the information and raising awareness among women in the target population. ${ }^{32}$ The recommendations in terms of the age of the target population, screening interval and availability of screening have been changing over the last 5 years, ${ }^{30}{ }^{32}$ which may contribute to women's difficulties in understanding the purpose and rules of cervical cancer screening.

Such differences in cervical screening guidelines across countries ${ }^{33}$ may cause confusion among migrants arriving in the UK. In addition, participation may be hindered by problems with accessing information, understanding the health care system, or a lack of prior experience with the NHS, ${ }^{34}$ as well as having a poor command of English, or lack of confidence in one's ability to communicate effectively. ${ }^{35-37}$

Despite the significant number of migrant women from the A8 and $\mathrm{A} 2$ countries living in the UK, little is known about their cervical screening needs. This study was set up in response to a call from Cancer Research UK for research aimed at exploring awareness of the NHSCSP among women from these countries. We took a qualitative approach to understand women's knowledge of NHS cervical screening services and their cervical screening behaviour, and triangulated their views with those of professionals working in the field. The work comprised three sub-studies: (1) an interview study with experts working with migrants from CEE countries, or in the cervical screening field; (2) a focus group study with CEE migrant women and (3) an in-depth interview study with women from the same CEE countries.
The aims of the study were to:

(1) Identify different patterns of screening attendance in women from CEE countries living in London using evidence from women themselves and professionals working in the field.

(2) Explore awareness about the NHSCSP in this group of women.

(3) Explore attitudes to the NHS programme and barriers to participation.

\section{Participants and methods}

\section{Study 1 - interviews with experts}

The participants were NHS and other professionals with knowledge of cervical screening among CEE migrants. NHS professionals were recruited through the Primary Care Research Network - Greater London and contacts of the researchers. We focused on primary care trusts with large populations of CEE migrants. For the NHS sample, we originally aimed to recruit practice nurses and GPs (i.e. those who deliver the screening programme in primary care). However, as recruitment proved to be difficult we also invited other primary care staff to participate. Non-NHS professionals were recruited through organisations working with CEE migrants. The sample size was dictated by the time and funding available, and we aimed to include a wide range of professions to identify a broad range of themes.

Nine semi-structured phone and two face-to-face interviews were conducted, guided by a topic guide developed to address the study aims. Participants were asked to express their opinions about CEE women's use of the NHSCSP.

\section{Study $\mathbf{2}$ - focus groups with women}

Five focus groups were conducted with Polish, Slovak and Romanian women living in London. We focused on Polish women as this is by far the largest CEE group in England. ${ }^{4}$ Slovakia was the A8 country with the next highest number of registrations under the Worker Registration Scheme between 2004 and 2007, and Romania is the larger of the two A2 countries. ${ }^{4}$ Participants were recruited through advertisements in shops and newspapers, and with the help of charitable organisations aimed at providing advice to CEE migrants. A 'snowballing' technique (whereby participants are asked to recruit their friends and colleagues to take part) was also used.

Focus groups were carried out in participants' native language structured around a topic guide. As this was an exploratory study about a relatively under-researched issue, the topic guide was developed with reference to the literature and research questions. The main topics explored were: knowledge of the NHSCSP, women's participation in cervical screening (in the UK and in their countries of origin), their experiences of and attitudes towards screening, barriers to screening, and possible improvements to the NHSCSP. Demographic 
information was collected using a short questionnaire. Women who took part were reimbursed for their time. Ethical approval was granted by the University College London (UCL) Research Ethics Committee.

\section{Study $\mathbf{3}$ - interviews with women}

The final study involved semi-structured interviews aimed at gaining a more in-depth understanding of women's screening participation. Recruitment methods were similar to those used in Study 2, and interviews were carried out in Polish for Polish participants and in English for Romanian and Slovak participants. The topic guide was similar to that used in the focus groups, and the study was approved by the UCL Research Ethics Committee as before. Women who took part in this study were reimbursed for their time.

Country of origin was the only inclusion criterion, partly because we wanted to include as wide a range of women as possible, and partly due to pragmatic concerns - it was difficult to recruit women at all so imposing strict criteria was not feasible. For the interview study, women from Slovakia and Romania had to have reasonably good English as the interviews were carried out in English and Polish only.

The three studies were carried out concurrently between December 2008 and October 2009. All the individual interviews were carried out by the first author, in Polish or English as appropriate. The Polish focus groups were carried out by the first author in Polish, and the Slovak and Romanian groups were moderated by native speakers with social science research backgrounds who had been thoroughly briefed about the aims of the study.

\section{Analysis}

All data were digitally recorded with participants' permission, translated where necessary and transcribed in English. We used framework analysis, ${ }^{38}$ a matrixbased approach to qualitative data synthesis. Emerging themes and subthemes were identified and used to create a thematic framework which was developed and discussed between two of the authors (MJ and JoW). The transcribed data were then summarised in thematic charts, where a column was created for each sub-theme and a row for each participant or focus group. This allows data examination either by a theme (looking vertically), or across a given participant/group (looking horizontally). Separate analyses were carried out for each sub-study, but all analyses were informed by issues emerging from the other studies. Interpretation of the data was discussed among all the authors.

\section{Results}

\section{Study 1}

Eleven participants were interviewed (five practice nurses, two consultants, a GP practice manager, a Polish gynaecologist, a bilingual advocate working with Polish migrants and a health care assistant). The interviews lasted 20-30 minutes. The main themes emerging from the analysis are described below.
Awareness of the NHSCSP

A number of health professionals felt that CEE women are aware of the NHSCSP, but not of the recommended screening frequency or age of the first screening test: "they're just unsure of how frequently they need to come for screening, that type of thing" (P7, practice nurse). [NB. Number refers to participant's ID number for Study 1.] A few professionals commented on CEE women expressing strong views about the age of eligibility of screening and screening frequency: "so they're outraged when they discover we don't do smears under the age of 25" (P1, associate specialist in family planning).

\section{Awareness of the purpose of screening}

Most of the experts reported that, in common with many British women, CEE women's knowledge regarding the rationale behind screening was not always accurate. One practice nurse said: "People think it's to pick up cancer and this sort of thing" (P11). Nevertheless, expert participants felt that most CEE women seemed aware of the need for screening, with many having participated in screening in their home countries: "so they may not know why you have screening exactly ... but they know they should go" (P1, associate specialist in family planning).

\section{CEE women's participation in the NHSCSP}

A central theme that emerged was that CEE women, with Polish being most frequently cited, are keen to participate in NHS screening. However, many experts reported that women were under-informed about the NHSCSP which is why, in many cases, they were screened opportunistically: "my feelings about the Eastern Europeans is that your point of contact is them asking for ... contraception, they're not coming in and saying, can you do a smear?"(P5, clinical lead in reproductive and sexual health). A few professionals suggested that some women do not take part in the NHSCSP because they use screening services in their home countries. However, it was also mentioned that they rarely provide their GPs with written results of screening tests done outside the UK. A bilingual advocate working with Polish women felt that women did not perceive cervical screening as a priority: "they seem not bothered about it, saying they will maybe do it in Poland" (P6).

Importantly, some health care professionals felt that their views on CEE women's screening participation might not be representative of the whole population, as the women they see are those who do attend primary care services: "we do see a lot of Eastern European women but [we don't know] whether that's the tip of the iceberg" (P5, clinical lead in reproductive and sexual health).

\section{Barriers to participation}

Language ability was the most frequently reported barrier to participation. Poor English could be a barrier 
Table 1 Demographic characteristics of participants in Studies 2 and 3 (total $n=52$ )

\begin{tabular}{|c|c|c|c|c|c|c|c|}
\hline \multirow{3}{*}{$\begin{array}{l}\text { Demographic } \\
\text { characteristic }\end{array}$} & \multicolumn{6}{|c|}{ Study 2 - focus groups } & \multirow{3}{*}{$\begin{array}{l}\text { Study } 3 \text { - interviews } \\
(n=20)\end{array}$} \\
\hline & \multirow{2}{*}{1} & \multirow{2}{*}{$\begin{array}{l}2 \\
\text { Polish }(n=8)\end{array}$} & \multirow{2}{*}{$\begin{array}{l}3 \\
\text { Polish }(n=6)\end{array}$} & \multirow{2}{*}{$\begin{array}{l}4 \\
\text { Romanian }(n=9)\end{array}$} & \multirow{2}{*}{$\begin{array}{l}5 \\
\text { Slovak }(n=5)\end{array}$} & \multirow[b]{2}{*}{ Total $(n=32)$} & \\
\hline & & & & & & & \\
\hline \multicolumn{8}{|l|}{ Country of origin } \\
\hline Poland & 4 & 8 & 6 & - & - & 18 & 11 \\
\hline Romania & - & - & - & 9 & - & 9 & 2 \\
\hline Slovakia & - & - & - & - & 5 & 5 & 7 \\
\hline \multicolumn{8}{|l|}{ Age (years) } \\
\hline $20-29$ & 2 & 1 & 1 & 4 & $5^{*}$ & 13 & 7 \\
\hline $30-39$ & 0 & 7 & 2 & 2 & 0 & 11 & 10 \\
\hline $40-49$ & 0 & 0 & 1 & 3 & 0 & 4 & 1 \\
\hline $50+$ & 2 & 0 & 2 & 0 & 0 & 4 & 2 \\
\hline \multicolumn{8}{|l|}{ Time in UK (years) } \\
\hline $1-2$ & 1 & 6 & 1 & 6 & 1 & 15 & 6 \\
\hline $3-4$ & 1 & 2 & 1 & 0 & 4 & 8 & 2 \\
\hline $5-9$ & 1 & 0 & 0 & 2 & 0 & 3 & 8 \\
\hline 10-19 & 1 & 0 & 2 & 1 & 0 & 4 & 4 \\
\hline $20+$ & 0 & 0 & 2 & 0 & 0 & 2 & 0 \\
\hline \multicolumn{8}{|l|}{ Employment status } \\
\hline Full-time & 1 & 0 & 2 & 2 & 2 & 7 & 6 \\
\hline Part-time & 0 & 0 & 1 & 3 & 1 & 5 & 3 \\
\hline Homemaker & 0 & 5 & 1 & 0 & 1 & 7 & 0 \\
\hline Self-employed & 1 & 3 & 1 & 4 & 0 & 9 & 7 \\
\hline Unemployed & 2 & 0 & 1 & 0 & 1 & 4 & 1 \\
\hline Student & 0 & 0 & 0 & 0 & 0 & 0 & 2 \\
\hline Missing & 0 & 0 & 0 & 0 & 0 & 0 & 1 \\
\hline \multicolumn{8}{|l|}{ Relationship status } \\
\hline Single & 2 & 1 & 3 & 5 & 4 & 15 & 5 \\
\hline Married/cohabiting & 2 & 6 & 0 & 2 & 1 & 11 & 9 \\
\hline Divorced & 0 & 1 & 2 & 2 & 0 & 5 & 1 \\
\hline Widowed & 0 & 0 & 1 & 0 & 0 & 1 & 0 \\
\hline Missing & 0 & 0 & 0 & 0 & 0 & 0 & 5 \\
\hline \multicolumn{8}{|l|}{ Has children } \\
\hline Yes & 2 & 8 & 2 & 2 & 1 & 15 & 6 \\
\hline No & 2 & 0 & 4 & 7 & 4 & 17 & 14 \\
\hline \multicolumn{8}{|l|}{ Registered with GP } \\
\hline Yes & 4 & 8 & 5 & 7 & 5 & 29 & 18 \\
\hline No & 0 & 0 & 1 & 2 & 0 & 3 & 2 \\
\hline
\end{tabular}

*The authors had difficulty accessing Slovak women and all those who took part in the focus group were aged in their twenties. GP, general practitioner.

to understanding the invitation, arranging an appointment or registering with the GP: "well obviously the letters we write are in English" (P8, practice nurse). The bilingual advocate reported that lack of availability of a translator was a barrier to some women seeing their GPs (P6).

Another issue raised was that CEE women are a transient population, moving house frequently and not informing their GPs, which means screening invitations may not reach them: "it is hard to keep track of women and keep track of their health needs" (P8, practice nurse).

Other cited barriers were similar to those established among British women, such as embarrassment or fear of results.

\section{Possible improvements to the NHSCSP}

A few health professionals felt that recording CEE women's ethnicity as 'White - Other' is problematic, as it does not enable the health system to make more fine-grained distinctions between groups in terms of access to NHS screening services, or to identify specific barriers by nationality. A few health professionals mentioned that sending the screening leaflet in women's native language might help to increase participation.

\section{Study 2}

Eighteen women took part in three Polish groups, nine women took part in a Romanian group and five in a 
Slovak group (see Table 1 for demographic characteristics). Women were aged 20-53 years old but the majority were in their 20s and 30s. Most had been in the UK for less than 5 years, but some for as long as 28 years. Focus groups lasted between 60 and 90 minutes. The main themes are described below.

\section{Awareness of the UK screening programme}

All participants were aware of cervical screening in England, and had been invited to take part. This is not consistent with the finding from Study 1 that many women only take part in screening when they access primary care services for contraception. Most women described the NHSCSP as different from screening in their home countries where they were used to having to take a more proactive role: "I immediately registered with a GP and they immediately sent me for screening, whereas in Poland at that time [18 years ago] you had to ask for that" (H, FG3 Polish). [NB. Initial refers to the individual in the group; FG3 denotes Focus Group 3.]

Women were impressed that screening in England is free and that invitations are sent automatically, but many were surprised that the test is carried out by a nurse or GP, rather than by a gynaecologist as would be the norm in their countries of origin: "I have been surprised when I went for screening ... Screening is done by a nurse, whereas in Poland it is done by a gynaecologist" (A, FG3, Polish). For some this was welcomed as it reduced embarrassment, while others found it frustrating not to have direct access to a gynaecologist. Consistent with the findings of Study 1 , many women thought 25 years was too late for screening to begin, with some suggesting it should start much earlier: "perhaps screening should be done after the first period" (U, FG2, Polish). Most were also used to more frequent screening and regarded 3 years between tests as too long: "it should be done every year" (Z, FG5, Slovak).

\section{Patterns of screening attendance}

Three main patterns of screening participation emerged.

\section{Screening in England alone}

Women who attended screening regularly in England did so because they found it 'easier', 'quicker' and 'less costly'. One participant said: "I used to think that when I go home I can get all the tests done over there, so wouldn't need to be registered here with a GP. Now I find it easier to go here" (A1, FG4, Romanian).

Other Romanian women said that they would never have screening in Romania - "S: I would never trust the doctors over there. V: Absolutely" (FG4). Health care in Romania was described as 'state run terror', 'brutal' and 'uncivilised' and women were pleasantly surprised by the kindness and care of NHS staff.

Screening in England and in the country of origin Some women, particularly the Polish participants, said that because they were unable to have more frequent screening on the NHS, they paid to have extra tests in Poland, where it was cheaper than having a private test in London: "I go for screening in England regularly. Sometimes I also top it up with some additional tests while I am in Poland" (K, FG1, Polish).

Screening in the country of origin or private clinics Women, in particular the Polish participants, who had never had NHS screening in England preferred to see a trusted gynaecologist in their home countries or attended private Polish gynaecology clinics in London and paid for screening (see also Barriers section below): "there are Polish clinics in London now, with Polish gynaecologists a lot of women go there even if it costs $£ 50 ”$ (H, FG3, Polish).

\section{Barriers to attendance in the UK}

Women cited many barriers to cervical screening that have been identified in the literature, but are not specific to this group, for example, embarrassment, fear and concern about discomfort. However, some barriers specific to migrant women emerged.

\section{Language}

Ease of communication was given as one reason for not attending NHS screening. One participant tried to explain why she always had screening in Poland but found it difficult to articulate the reasons: "The GP I have here is good but ... I don't really trust, I don't know ...there's something in me, I just know that in Poland they will do all the tests... maybe because it is in Polish, but I speak English fluently" (J, FG1, Polish). It was also noted that poor language skills might discourage some CEE women from even registering with a GP, and that many others were not registered because they moved house frequently. Interestingly, there was disagreement among participants about whether a translator was necessary at a screening appointment. It seemed, then, that practical language barriers were important for some women, but that even where women were able to speak English, there were additional barriers to communication operating at a more subtle level. In some cases women reported that health professionals responded negatively toward people whose English was poor, and thought this might have an impact on women's inclination to access screening: "some doctors are mean towards someone who is shy or can't speak English well” (A, FG3, Polish).

Negative attitudes to the NHS

Lack of confidence in NHS health professionals was a pervasive theme and is illustrated below in an excerpt from Polish FG1, when women were asked what they would do if they had an abnormal screening result:

KR: "I would definitely contact the GP, but if after that I still felt uncertain, I would travel to Poland to have another examination."

J: $\quad$ "I would do the same too ... I would go to my GP ... and I would go to Poland to have another examination, to make sure." 
Some women described experiences in England that had made them distrustful of the NHSCSP and follow-up care. One woman reported having been monitored for a cervical abnormality in England, but then receiving immediate treatment when she went to Slovakia. She said that "the doctors in Slovakia were very surprised that I was left up to that stage [of abnormality] without any treatment in Britain". After this experience she said: "I decided not to go for this test in Britain any more and refused the last invitation from my GP. I travel home regularly ... to have it done over there" (A, FG5, Slovak).

\section{Lack of awareness of entitlements}

There was a belief that some migrant women might not know what their rights to health care in Britain are. One woman said: "I did not know that the blood tests are free, for example” (A2, FG4, Romanian). But most had, in fact, been invited for screening either via the call-recall system, or when they registered with a GP.

\section{Time pressures}

For some women the reasons for not participating in screening were more pragmatic. Taking time off work for screening was difficult, or would mean forgoing income which they could not afford to lose, so they found it easier to visit the doctor and have screening while visiting home.

One Polish woman summed up many of these barriers when she said: "I have a lot of colleagues who aren't at all registered with a GP here because they ... work all the time and say they prefer to go to Poland once a year, when during 1 week they do all the medical tests with all the doctors. They just don't trust the British health care. There is a language barrier or they don't have time to go, or even think they don't need to" (R, FG1, Polish).

\section{Study 3}

Twenty women took part in in-depth interviews: 11 Polish, seven Slovak and two Romanian (Table 1). The mean age of participants was 36 years (Polish), 27 years (Slovaks) and 38 years (Romanians). Length of stay in the UK ranged from less than a year to over 15 years. Interviews lasted 25-60 minutes and the main emergent themes are described below.

\section{Awareness of cervical screening and experience of cervical screening in the UK}

Most women seemed aware that the purpose of cervical screening is to detect early precancerous changes, but some also thought that the test is aimed at detecting cervical cancer. In the context of individual interviews rather than focus groups, we were able to probe women's beliefs more deeply and identify other misconceptions. Some women believed that the test was a more general check-up: "Well, screening is carried out to determine ... if there are any changes in the reproductive organs... whether bacterial flora is fine ... but it is also a method of cancer prevention and that sort of thing” (P7, Polish). [NB. Number refers to participant's ID number for Study 3.]

Most of the comments about the NHSCSP were positive. Women were happy that the programme is organised and free. The opening times and locations for screening were perceived as convenient by most. Reminders were generally welcomed: "when I missed my test they kept sending me reminders, which is good, as they motivated me to go" (P8, Polish).

Many women also felt that the test is carried out in a friendly and respectful manner. The explanation of the procedure was especially appreciated: "the nurse has always explained everything and showed me what she was going to do ...so I always felt prepared for what was going to happen next" (P6, Polish). Positive experiences were not universal, however, and one Slovak woman felt that she had not been well treated: "for [the doctor] it was something very routine but for the person who is coming for the first time for the test ... she was not trying ... to explain something or be helpful" (P16, Slovak). Interestingly, many women felt that screening was well promoted in the UK while it was rarely discussed in their countries of origin.

Some criticisms were also voiced. In particular, many women corroborated the earlier finding that the screening interval is too long, and that the age of 25 years is too late for the first test. One woman explained that she believed cancer could develop and become terminal within the 3 years between screens, citing Jade Goody as an example: "[screening should be] more often than 3 years, definitely. And, you know, even the case of Jade Goody ... I think she even was fighting for less than 3 years, wasn't she?" (P20, Slovak). [NB. Jade Goody was a British reality TV personality who died of cervical cancer at the age of 27 years in March 2009.] Other criticisms included a long waiting time for the results letter, and the letter not being detailed enough.

\section{Patterns of attendance}

The individual interviews offered a more detailed understanding of the patterns of screening participation described in Study 2.

\section{Screening in England alone}

These women typically referred to the fact that they 'live here' and therefore access health care services in this country. All these women had been in the UK for at least 2 years and tended to be positive about the NHS. A typical comment was: "I go to the doctor here [GP], I live here. I live here. I use all services here, food and so on so why would I go for screening there?" (P9, Polish). However, one Slovak woman said that she still mainly used the Slovak health care system, but was willing to have screening in the UK because it was preventive rather than diagnostic (P11, Slovak).

\section{Screening in England and in the country of origin}

This pattern seemed less common among the women interviewed than those in the focus groups (perhaps 
due to sampling differences). One Polish woman (P12) expressed similar views to those in the focus groups and said that although she had taken part in screening here and would continue to do so, she would go to Poland to check the result if she had an abnormality, and would have screening there if she was visiting for long enough: "if I was staying there for a longer period of time and if I had time to go then I would go for private screening in Poland...to confirm the results from here" (P12). She said she had more trust in the Polish system and that her friends from other countries had similar views.

\section{Screening in the country of origin only}

Women's reasons for having screening only in their home countries varied. A particularly important barrier to participation in the UK was lack of acculturation or what a Romanian participant described as 'fractured living' (P17): "you live this kind of fractured existence with gaps in what is your life in England, and I guess it kind of also makes you forget about ... certain things that should be in your annual calendar" (P17, Romanian). This was perhaps most common in women who had not decided whether they were going to stay in England or go back to their home countries: "...they are still not decided where to live and some of them... already [know] after they come here that they want to go back and they go back several times a year and always visit the dentist or the GP and have everything done... They live life like this, in two countries" (P19, Slovak). For others, it was simply more convenient to have a full gynaecological check-up when they visited their home countries.

One Polish woman spoke no English, did not understand that she could be screened at her GP surgery, and was not confident about travelling to a clinic in an unfamiliar area. She had no one to translate for her, so language was described as a significant barrier.

Two of the Slovak women talked about a lack of trust in the NHS. One mentioned that although she used the NHS when she was ill, she had screening and checkups in Slovakia, while the other said that even if she was ill she would go to Slovakia for treatment. Two other Slovak women, who did have screening in the UK, mentioned friends who travelled back to Slovakia regularly for health care, and this was perceived to be a common pattern of behaviour. Many women of all three nationalities lacked trust in the NHS, often citing poor hygiene and a perceived tendency to treat every illness with paracetamol. In many cases, women's negative opinions regarding the NHS were based on stories that they heard from other people rather than their own experiences.

\section{Discussion}

A fairly consistent picture of women's cervical screening knowledge and behaviour emerged from the three studies. Where discrepancies occurred, this was probably due to the women who took part in the studies generally being engaged with the screening programme, whereas the health professionals were able to report on the behaviour of women who only took part when invited opportunistically.

Participants seemed aware of the importance of cervical screening without necessarily being fully informed about the programme, or its exact purpose. This phenomenon has been reported in British women too. ${ }^{39}$ The use of in-depth interviews allowed us to move beyond the general comments of professionals in the field to a more detailed understanding of women's beliefs and perceptions, such as the idea that the test can detect more than just precancer.

In contrast to the NHSCSP recommendations regarding the interval between screening tests and the age at which screening begins, there was a pervasive view that screening should begin before the age of 25 years, and should be more frequent than every 3 years. These beliefs are likely to stem from differences in cervical screening guidelines in women's countries of origin, and may in part explain some women's use of more frequent (usually opportunistic) screening when they visited home.

Although some women were fully engaged in the NHSCSP, many used screening services in their home countries either instead of, or in addition to NHS screening. Women who took part in screening solely in the UK often used the phrase 'I live here' to explain this, demonstrating a desire to engage with all aspects of British life. They also tended to have lived in the UK for at least 2 years, which is consistent with findings that screening participation is related to the length of residence in a Canadian study. ${ }^{40}$ By contrast, those who continued to have screening in their home countries often had ambivalent or negative attitudes towards the NHS, or were unsure about their intentions to stay in the UK, so understandably maintained links with health care systems in their countries of origin. One participant used the phrase 'fractured living' to describe the way in which some migrants lead two separate lives - one in the UK and one in their country of origin. Further work might usefully consider these patterns of health care utilisation in the context of broader issues of acculturation and sociocultural adaptation..$^{41}$ It is also important to know whether women's choices about screening have an impact on cervical cancer outcomes. To our knowledge, there are no data available about the relative incidence of cervical cancer or its precursors among women from CEE in the UK so it is unclear whether a choice not to engage fully in the NHS programme is likely to have an impact on health outcomes or not.

Women who did not participate in the NHSCSP tended to lack trust in the NHS, but also cited communication issues as barriers to participation. Although only a few women in the study cited language as a barrier to screening for themselves, many believed that poor English and lack of available translators was a barrier for others. Health professionals working in the screening service commented that the current system 
of recording CEE women's ethnic group as 'White Other' makes it impossible to identify the language needs of these women, although it should be noted that the NHS cervical screening information leaflet is available online and as an audio CD in Polish. Better recording of ethnic group is essential if inequalities in screening participation, and in cancer morbidity and mortality, are to be monitored and addressed.

Because we only managed to recruit 11 Romanian and 12 Slovak women, with the Slovak women all being very young, it was not possible to draw firm conclusions about differences between the nationalities. Nonetheless, women's attitudes to the health care system in their country of origin seemed to be important in explaining their screening behaviour. The Romanian women tended to have very negative views about health care in Romania, and mainly used the NHS for screening, whereas the young Slovak women seemed more likely to return to Slovakia not only for screening, but for other aspects of their health care. Participating in screening at home was often motivated by a desire for more frequent tests than are offered on the NHS or a preference for screening by a gynaecologist. This is in line with past studies which have identified similar issues, including the role of GPs, differing prescribing patterns and antipathy towards 'patient-centred' rather than more paternalistic consultations. ${ }^{342}$ These findings emphasise that CEE women are a heterogeneous group, and that it is important for health professionals to be aware of the cultural differences underlying their screening expectations.

Consistent with previous studies, practical as well as psychological barriers were reported by some women, indicating that any attempts to address these will benefit CEE women. ${ }^{12} 172021$ A few women were not happy with the waiting time for the results letter, the test being carried out by a nurse and the cleanliness of screening instruments. These concerns are shared by British women to some extent, ${ }^{19}$ but are also likely to stem in part from the differences of screening practices in CEE countries.

This study is not without limitations. Participant recruitment proved to be challenging. In Study 1, we aimed to gain a range of different perspectives so we tried to recruit a heterogeneous group of participants, but the small and very diverse sample hinders the interpretation of the findings. We were only able to include Slovak women in their twenties. Most of them had only been in the UK for a short time and the majority were university educated. This limits the generalisability of the findings. Women of all three nationalities tended to be in their twenties and thirties so few conclusions can be drawn about older women. In addition, all the women were recruited in London. Because screening participation and barriers may be different in other areas of the UK, future research should address this issue urgently, as a large proportion of CEE migrants live outside London. ${ }^{4}$
The majority of the participants were registered with a GP and our findings cannot be extrapolated to Polish, Romanian or Slovak women who are not registered with a doctor in the UK, or to women from other CEE countries. Finally, the interviews with Polish women and all the focus groups were conducted in the women's native language and were then translated into English for analysis. This could have impacted on data interpretation but our study team benefited from three bilingual speakers of Polish and English, which we believe adds to the validity of the interpretation, at least in respect to the Polish sample.

Notwithstanding these limitations, the studies benefited from the inclusion of both women and professionals to provide two different perspectives, and also had the advantage that all the focus groups and most of the interviews were carried out in women's native languages. We included women from a range of backgrounds, some of whom did not attend screening regularly, but more work is needed to identify barriers in women who have never been screened. Future work could also usefully examine the impact of factors that might affect women's interactions with the NHS, such as having children and being married to a UK national.

\section{Conclusions}

Although Polish, Romanian and Slovak women living in London are aware that cervical screening is available to them on the NHS, their utilisation of the service varies. From the health care professional perspective more needs to be done to increase their cultural competence, enabling them to minimise cultural barriers to screening. More work is also required to help women understand the reasons for the 3-year screening inter$\mathrm{val}$, and to ensure that language is not a barrier to participation.

Acknowledgements The authors are grateful to Stefania Hirtopanu and Danica Kevicka for their help with recruiting, moderating, translating and transcribing two of the focus groups. The authors also thank the Stockwell Partnership for their help with recruitment and for providing a location of one of the Polish groups, and all the women who gave their time to take part in this research.

Funding The study was funded by a grant from the Cancer Research UK Prevention and Public Health Policy Advisory Group (C1418/A9847). Jo Waller is the guarantor.

Ethical approval The study was approved by the National Hospital for Neurology and Neurosurgery and Institute of Neurology Joint Research Ethics Committee. Ethical approval was granted by the University College London (UCL) Research Ethics Committee.

Competing interests None.

Provenance and peer review Not commissioned; externally peer reviewed. 
Open access This is an Open Access article distributed in accordance with the Creative Commons Attribution Non Commercial (CC BY-NC 3.0) licence, which permits others to distribute, remix, adapt, build upon this work noncommercially, and license their derivative works on different terms, provided the original work is properly cited and the use is non-commercial. See: http://creativecommons.org/licenses/by$\mathrm{nc} / 3.0 /$

\section{References}

1 Hargreaves S, Friedland JS, Gothard P, et al. Impact on and use of health services by international migrants: questionnaire survey of inner city London A\&E attenders. BMC Health Serv Res 2006;6:153.

2 Leaman AM, Rysdale E, Webber R. Use of the emergency department by Polish migrant workers. Emerg Med J 2006;23:918-919.

3 Matthews R. Migrant workers: impact on local areas and services. Report to the Audit Commission on Study Visit to Hull and East Riding. London, UK: Audit Commission, 2006.

4 Pollard N, Latorre M, Sriskandarajah D. Floodgates or turnstiles? Post-EU enlargement migration flows to (and from) the UK. 2008. http://www.ippr.org.uk/publicationsandreports/ publication. asp? id $=603$ [accessed 4 May 2011].

5 Gillingham E. Understanding A8 migration to the UK since accession. 2010. http://www.ons.gov.uk/ons/rel/migration1/ migration-statistics-quarterly-report/november-2010/ understanding-a8-migration-to-the-uk-since-accession.pdf [accessed 4 May 2011].

6 Lanz S, Gullen R. The extent, size and characteristics of the migrant workforce in the Vale of Evesham. http://wychavon. whub.org.uk/home/wdc-rural-migrant-final-report-may06.pdf. 2006 [accessed 4 May 2011]

7 Lakasing E, Mirza ZA. The health of Britain's Polish migrants: a suitable case for history taking and examination. Br J Gen Pract 2009;59:138-139.

8 The NHS Information Centre, Screening and Immunisation Team. Cervical Screening Programme England 2010-11. 2011. http://www.ic.nhs.uk/webfiles/publications/008_Screening/ cervscreen1011/cerv_scrn_eng_2010_11_rep_v1.1.pdf [accessed 7 December 2011].

9 Behbakht K, Lynch A, Teal S, et al. Social and cultural barriers to Papanicolaou test screening in an urban population. Obstet Gynecol 2004;104:1355-1361.

10 Oscarsson MG, Benzein EG, Wijma BE. Reasons for nonattendance at cervical screening as reported by non-attendees in Sweden. J Psychosom Obstet Gynaecol 2008;29:23-31.

11 Pearlman DN, Clark MA, Rakowski W, et al. Screening for breast and cervical cancers: the importance of knowledge and perceived cancer survivability. Women Health 1999;28:93112.

12 Sutton S, Rutherford C. Sociodemographic and attitudinal correlates of cervical screening uptake in a national sample of women in Britain. Soc Sci Med 2005;61:2460-2465.

13 Lovell S, Kearns RA, Friesen W. Sociocultural barriers to cervical screening in South Auckland, New Zealand. Soc Sci Med 2007;65:138-150.

14 Orbell S. Cognition and affect after cervical screening: the role of previous test outcome and personal obligation in future uptake expectations. Soc Sci Med 1996;43:1237-1243.

15 Tacken MA, Braspenning JC, Hermens RP, et al. Uptake of cervical cancer screening in The Netherlands is mainly influenced by women's beliefs about the screening and by the inviting organization. Eur J Public Health 2007;17: 178-185.
16 Wardle J, McCaffery K, Nadel M, et al. Socioeconomic differences in cancer screening participation: comparing cognitive and psychosocial explanations. Soc Sci Med 2004;59:249-261.

17 Waller J, Bartoszek M, Marlow L, et al. Barriers to cervical cancer screening attendance in England: a population-based survey. J Med Screen 2009;16:199-204.

18 Yu CK, Rymer J. Women's attitudes to and awareness of smear testing and cervical cancer. Br J Fam Plann 1998;23:127-133.

19 Summers A, Fullard B. Improving the coverage and quality of cervical screening: women's views. J Public Health Med 1995;17:277-281.

20 Fylan F. Screening for cervical cancer: a review of women's attitudes, knowledge, and behaviour. Br J Gen Pract 1998;48:1509-1514.

21 Walsh JC. The impact of knowledge, perceived barriers and perceptions of risk on attendance for a routine cervical smear. Eur J Contracept Reprod Health Care 2006;11:291-296.

22 Olowokure B, Caswell M, Duggal HV. What women want: convenient appointment times for cervical screening tests. Eur J Cancer Care (Engl) 2006;15:489-492.

23 Oscarsson MG, Wijma BE, Benzein EG. Nonattendance in a cervical cancer screening program - what happens if women's requirements are met? Health Care Women Int 2008;29:183-197.

24 World Health Organization. Strategies to Improve and Strengthen Cancer Control Programmes in Europe: Report of a WHO Consultation. Geneva, Switzerland: World Health Organization, 2003.

25 Bardin A, Vaccarella S, Clifford GM, et al. Human papillomavirus infection in women with and without cervical cancer in Warsaw, Poland. Eur J Cancer 2008;44:557-564.

26 Peto J, Gilham C, Fletcher O, et al. The cervical cancer epidemic that screening has prevented in the UK. Lancet 2004;364:249-256.

27 Bielska-Lasota M, Krynicki R, Rabczenko D, et al. Survival of cervical cancer patients in selected regions of Poland in 19901996, in relation to some prognostic factors [in Polish]. Przegl Epidemiol 2004;58:523-536.

28 Spaczynski M, Kotarski J, Nowakowski A, et al. Recent trends in cervical cancer control in Poland. Entre Nous - The European Magazine for Sexual and Reproductive Health 2007;64:22-24.

29 Todorova I, Baban A, Alexandrova-Karamanova A, et al. Inequalities in cervical cancer screening in Eastern Europe: perspectives from Bulgaria and Romania. Int J Public Health 2009;54:222-232.

30 Bastos J, Peleteiro B, Gouveia J, et al. The state of the art of cancer control in 30 European countries in 2008. Int J Cancer 2010;126:2700-2715.

31 Spaczynski M, Karowicz-Bilinska A, Rokita W, et al. Attendance rate in the Polish Cervical Cancer Screening Program in the years 2007-2009 [in Polish]. Ginekol Pol 2010;81:655-663.

32 Nicula FA, Anttila A, Neamtiu L, et al. Challenges in starting organised screening programmes for cervical cancer in the new member states of the European Union. Eur J Cancer 2009;45:2679-2684.

33 Hakama M, Coleman MP, Alexe DM, et al. Cancer screening: evidence and practice in Europe 2008. Eur J Cancer 2008;44:1404-1413.

34 O’Donnell CA, Higgins M, Chauhan R, et al. Asylum seekers' expectations of and trust in general practice: a qualitative study. Br J Gen Pract 2008;58:e1-e11. 
35 Maxwell CJ, Bancej CM, Snider J, et al. Factors important in promoting cervical cancer screening among Canadian women: findings from the 1996-97 National Population Health Survey (NPHS). Can J Public Health 2001;92:127-133.

36 Sproston KA, Pitson LB, Walker E. The use of primary care services by the Chinese population living in England: examining inequalities. Ethn Health 2001;6:189-196.

37 Quan H, Fong A, De Coster C, et al. Variation in health services utilization among ethnic populations. CMAJ 2006;174:787-791.

38 Ritchie J, Spencer L. Qualitative data analysis for applied policy research. In: Bryman A, Burgess R (eds), Analysing Qualitative Data. London, UK: Routledge, 1994;173-194.

39 Philips Z, Avis M, Whynes DK. Knowledge of cervical cancer and screening among women in east-central England. Int J Gynecol Cancer 2005;15:639-645.
40 McDonald JT, Kennedy S. Cervical cancer screening by immigrant and minority women in Canada. J Immigrant Minority Health 2007;9:323-334.

41 Berry JW. Immigration, aculturation and adaptation. Applied Psychology 1997;46:5-68.

42 O'Donnell CA, Higgins M, Chauhan R, et al. "They think we're OK and we know we're not”. A qualitative study of asylum seekers' access, knowledge and views to health care in the UK. BMC Health Serv Res 2007;7:75. 